\title{
Cultura material e historia de la experiencia
}

\author{
Agustín Escolano Benito*
}

\section{Resumen}

Este trabajo trata de plantear, desde una orientación fenomenológica y hermenéutica de la historia de la educación, una construcción empírica de la cultura de la escuela a partir del estudio de las prácticas formativas y de los materiales o sus representaciones en que se ha objetivado el acervo de fuentes del pasado. Propone poner en valor las cosas que han sido creadas por los docentes como soportes de sus acciones, esto es, como materialidades adheridas a su tékhne profesional y como patrimonio histórico de su tradición artesanal. Los objetos servirían al historiador como sintetizadores que comportan huellas a interpretar en una semiosis hermenéutica de la cultura pragmática de la educación. Ello comporta su revalorización como patrimonio común de todos los sujetos escolarizados y como bien por tanto para la reconstrucción de la memoria de la ciudadanía ilustrada en una sociedad democrática.

Palabras clave: cultura empírica de la escuela, etnohistoria y hermenéutica del patrimonio escolar, objetos-huellas como sintetizadores de la pragmática escolar, iconografías, historia de la experiencia educativa

* Director del Centro Internacional de la Cultura Escolar (CEINCE). e-mail: ceince@ ceince.eu 


\title{
Material culture and history of the experience
}

\begin{abstract}
This article tries to raise, from a phenomenological and hermeneutic orientation of the history of education, an empirical construction of the culture of the school. The work exposes the formative and material school practices and their representations from sources of the past. The article is proposed to put in value the things that have been created by the teachers as supports of their actions adhered to their professional tékhne and as historical heritage of their craft tradition. The objectives of the work would serve to the historian as synthesizers that involve traces to interpret in a hermeneutic semiosis of the pragmatic culture of education. This entails its revaluation as a common heritage of all subjects enrolled in school and as well for the reconstruction of the memory of the citizenship illustrated in a democratic society.
\end{abstract}

Keywords: empirical culture of the school, ethnohistory and hermeneutics of school heritage, school pragmatics, iconography, history of the educational experience 


\section{El retorno a la experiencia}

La escuela es en primer término una institución construida a través de las prácticas que desempeñan los actores que cohabitan en ella y que se manifiestan en las materialidades que la conforman y que apoyan esas prácticas. Este ensayo se origina en el debate suscitado en nuestro tiempo en torno a la necesidad de repensar el sentido y la significación de la escuela a partir de su cultura empírica y material, en el contexto más general y holístico de una historia de la experiencia, un enfoque que se ha hecho cada vez más necesario plantear en las investigaciones acerca del pasado de las instituciones de formación, dada la expansión a escala global de las iniciativas que tienen que ver con los centros de memoria y la museografía pedagógica. La vuelta a la experiencia a través de los objetos y las representaciones en que ha quedado materializada la vida de la escuela es sin duda un giro historiográfico saludable que requiere cuidadosos análisis.

Tal planteamiento sugiere la necesidad de relacionar la historia material con el amplio campo de la empeiria, bajo la exigencia de sustentar el trabajo académico en la seguridad metodológica que ofrecen las positividades, fuentes factuales para la construcción de una cultura pragmática de la escuela. Implica asimismo la introducción de un mayor rigor en la interpretación de los hechos asociados a las materialidades etnográficas. La nueva expectativa se suscita tras haber cuestionado la legitimidad, dominante en la historiografía de épocas anteriores, de los análisis de orientación teórica y política con que se examinó el pasado del mundo educativo, hasta que se problematizó el valor de los discursos tradicionales, y en parte también de los modernos, en los que se venía sustentando una determinada visión de la cultura escolar. La vieja historia excluía además la consideración de las cuestiones que afectan a las emociones y los sentimientos, que se consideraron elementos irracionales, aunque formaran parte del mundo de la vida y de la experiencia. No es del todo nueva esta orientación hacia la fenomenología, sobre todo si recordamos los combates para fundar la nueva historia que Lucien Febvre situó, hace ya más de 
medio siglo, más allá de lo que el conocido fundador de Annales llamaba "el inútil torneo de las ideas" (Febvre, 1953, p.115).

Las dos últimas décadas de investigación han tratado sin embargo de hacer visibles los testimonios factuales de la educación, y han explorado la posibilidad de descubrir en ellos las claves semióticas que puedan permitir comprender e interpretar la significación y el sentido implícito en las prácticas asociadas a los objetos y las representaciones, así como la relación afectiva de estos datos con los sujetos que los utilizaron. Tal hermenéutica no se ha llevado a cabo siempre con el rigor epistémico exigible a toda operación intelectual crítica, al no traspasar con frecuencia estos análisis el nivel de las descripciones etnográficas primarias y de las propuestas representativas que se postularon en las exposiciones y los centros de memoria de la escuela que han venido ofreciendo una imagen pública del pasado de los procesos de la formación humana.

Hay que asumir que a la nueva generación de historiadores de la educación le ha correspondido, en la crisis de la posmodernidad, volver la mirada hacia fuentes que habían quedado en la marginalidad de los programas de investigación. Tales restos fueron más bien percibidos hasta hace poco tiempo como rastros residuales del mundo de la vida cotidiana en las instituciones pedagógicas, nunca relevantes para poder analizar, explicar y comprender el pasado de la escuela, un pasado que sólo era inteligible desde perspectivas históricas más culturales o sociales, e incluso más ideológicas, pero no en su propia realidad efectual.

Como han observado algunos analistas del pasado, los historiadores de la educación siempre se detuvieron en el umbral de la escuela, y nunca decidieron entrar en ella, al considerar tal vez que lo que en su interior pudo ocurrir en el pasado solo era un reflejo banal y efímero de las ideas o normas que quisieron fundar desde el exterior un modelo formativo y una determinada gobernanza de la educación. En el mejor de los casos, para la historia neoidealista anterior, estas fuentes se adscribían al grosero y prescindible mundo de la acción. De este modo, las materialidades solo eran curiosidades anticuarias que, en determinados supuestos, 
podrían recogerse en museos ad hoc destinados a guardar el utillaje ergológico de los oficios de la vida cotidiana y de las artes del hacer -también del arte de la enseñanza-, para ilustración, cultivo y entretenimiento de la ciudadanía.

No obstante lo anterior, los historiadores de las últimas décadas introdujeron la sospecha de que incluso entre los papeles del archivo se veía asomar a veces la voz de las prácticas y la presencia soterrada de los condicionamientos materiales entre los que se desenvolvía el mundo de la experiencia en las instituciones de formación. Así se abrió paso entre nosotros la llamada etnohistoria, una línea de investigación que acercaba la historia a la antropología cultural. La pragmática de la escuela estaba semioculta, pero subyacente, entre los papeles y entre los discursos y las normas, pero era todavía mucho más evidente en los objetos y las iconografías que estudiaban la antropología cultural de lo material y el llamado pensamiento visual. Así emergió la etnohistoria como línea y campo intelectual de estudios acerca del pasado de la educación.

El conocido antropólogo Bernard S. Cohn, de la Universidad de Oxford, escribió en 1962 un lúcido artículo que tituló "Un antropólogo entre los historiadores", en el que trataba de mostrar cómo este nuevo científico social podía tratar los materiales obtenidos en archivos, bibliotecas y museos sirviéndose del modelo del cuaderno de campo que formaba parte de su habitus académico. Él fue uno de los primeros en hablar de la etnohistoria, una línea epistémica que sugería desformalizar en cierto modo el trabajo intelectual y que invitaba a llevar a las aulas universitarias objetos e imágenes de las cosas, y no solo ideas y valores normativos. También aconsejaba observar los materiales y tejer con ellos un modelo interpretativo, que no tenía que ser coincidente con el que los historiadores tomaban como sistema de partida, ni con el orden cronológico convencional. Las preguntas históricas podían tener mejor respuesta en el cuaderno de campo sacado de la observación de las fuentes materiales que en la biblioteca o en el archivo. Y además, los historiadores podrían ampliar su horizonte hermenéutico si dialogaban con otros especialistas como los psicólogos, 
los médicos, los sociólogos y los antropólogos, un viejo consejo que curiosamente empieza ahora a cumplirse en los nuevos abordajes como los que se apoyan en la historia material, la antropología visual o la historia de las emociones (Cohn, 1962).

El presente trabajo quiere contribuir a desvelar esta laguna de la historia escolar, tal vez la más inexcusable por ser la que muestra sus señas de identidad del modo más visible: la cultura material de la escuela. Pero lo quiere abordar desde la intención de ahondar en el sentido y en los significados de los restos en los que ha quedado reflejada, como exponentes que son de una cultura implícita en ellos, esto es, como registros de las positividades que implementaron los procesos educativos. El análisis se inserta en el contexto teórico e historiográfico de una deseable historia de la experiencia: la que afecta a las materialidades en las que se dota de fisicalidad y simbolismo al conjunto de herramientas que acompaña al arte y oficio de la enseñanza y a la aventura humana del aprendizaje, aspectos ambos del máximo interés no solo para la historia educativa sino también para el conocimiento de las prácticas asociadas a la construcción antropológica del sujeto moderno, cuestión nuclear para todas las ciencias sociales.

La historiografía tradicional se apoyó sobre todo en textos, y de modo especial en las escrituras de los sujetos notables, no tanto en las escrituras ordinarias ni en las de los manuales del común de la sociedad, entre las que hay que contar las que se produjeron o circularon en el ámbito de la escuela. Prestó más atención, diríamos recordando a Michel Foucault, a las palabras que a las cosas, olvidando que en todo discurso hay siempre implícito un modo de hacer, y que todo hacer se sustenta inexcusablemente en una relación que los sujetos entablan con los objetos materiales que ellos producen o con los que, aunque elaborados por otros, se relacionan. Este ensayo busca pues fundamentar la conexión que se da entre la experiencia, las materialidades y los discursos que contribuyen a la construcción de una cultura empírica de la escuela (Escolano, 2017). 


\section{El valor de las cosas}

Las cosas son mediaciones entre las prácticas y los discursos. Michel Foucault habló de la "escritura" de las cosas, ya que según él ellas mismas comportan un lenguaje, a través del cual "ocultan y manifiestan su enigma" (Foucault, 1968). En toda obra humana, incluso en la intelectual, y desde luego en la pedagógica, hay una relación material y comunicativa con las cosas del mundo de la vida. Las gentes aprenden de sí mismas y de los demás, como señaló Richard Sennett, a través de las realidades materiales que producen o utilizan, o sea, de la cultura que en ellas se alberga (Sennett, 2006). Más aún, como sugieren las obras de este acreditado sociólogo, las relaciones que los humanos entablan en la producción de los materiales son las que pautan los códigos de sociabilidad de los sujetos, es decir, los modelos de comunicación. Una escalera -el ejemplo objetual que elige Sennett para ilustrar lo anterior- solo puede ser fabricada e instalada in situ mediante una acción cooperativa de los individuos que intervienen en su construcción y montaje, siendo al final este objeto estructural de toda casa el resultado de la interacción coordinada que fusiona su diseño de fabricación con los movimientos de los operarios que la instalan en el inmueble.

Algunos objetos de la escuela también se corresponden con esa misma lógica de producción y uso que subyace en todas las artesanías, y por eso comportan mensajes que hay que descifrar porque en ellos están los significados de la cultura que instrumentan. Estos materiales son, por un lado, el resultado de una obra hecha con pericia artesanal u oficio, pero tanto su diseño y fabricación como su instalación, así como el uso que de ellos se hace por parte de los enseñantes y los alumnos en las aulas, abocan a procesos de socialización que afectan a la operativa que los produce y a la tékhne de quienes los utilizan. En estos objetos se encarna la relación existente entre la cultura material y los modos de relación social, y en ellos hay implícito un capítulo importante de la historia de la experiencia de la humanidad. 


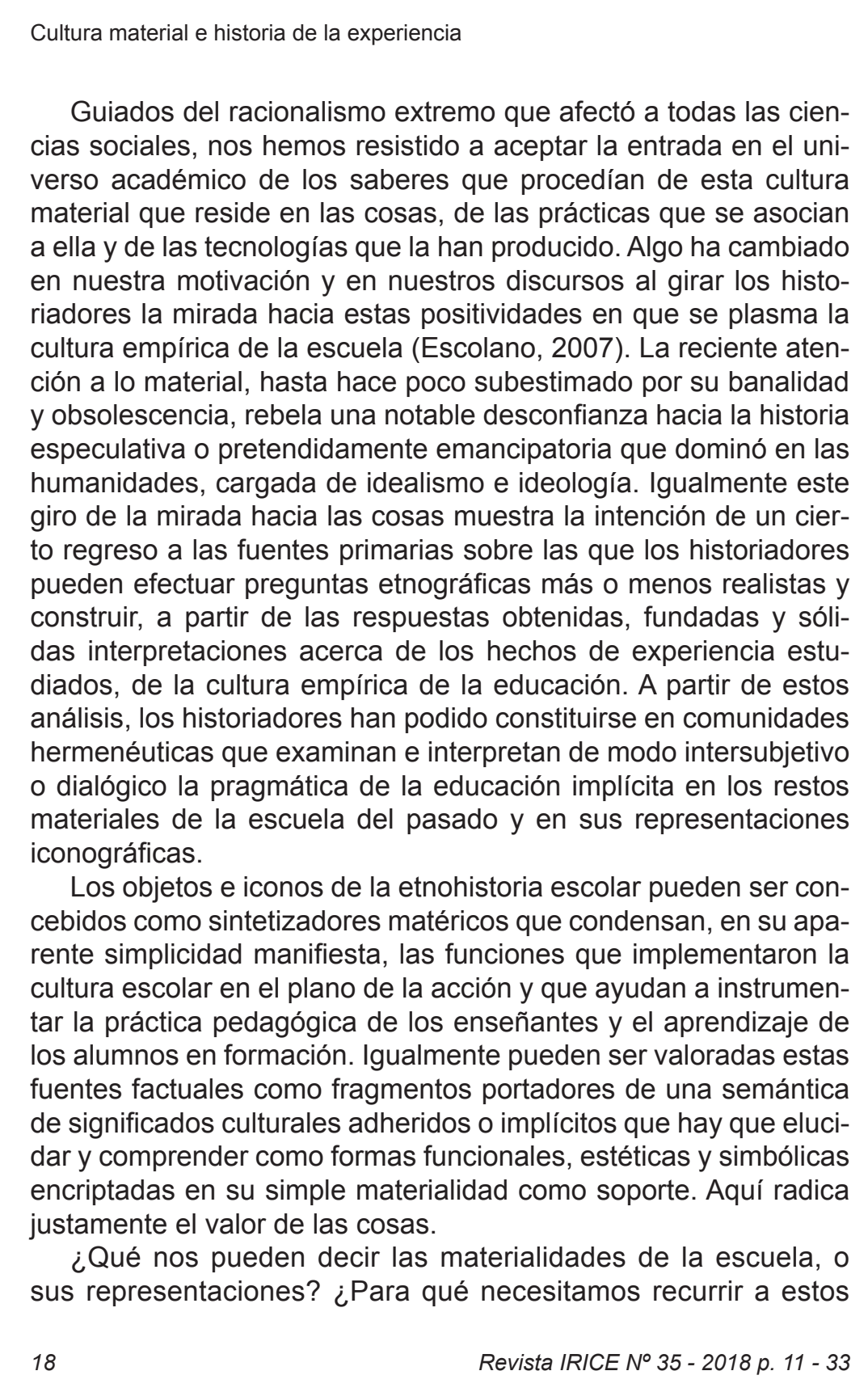




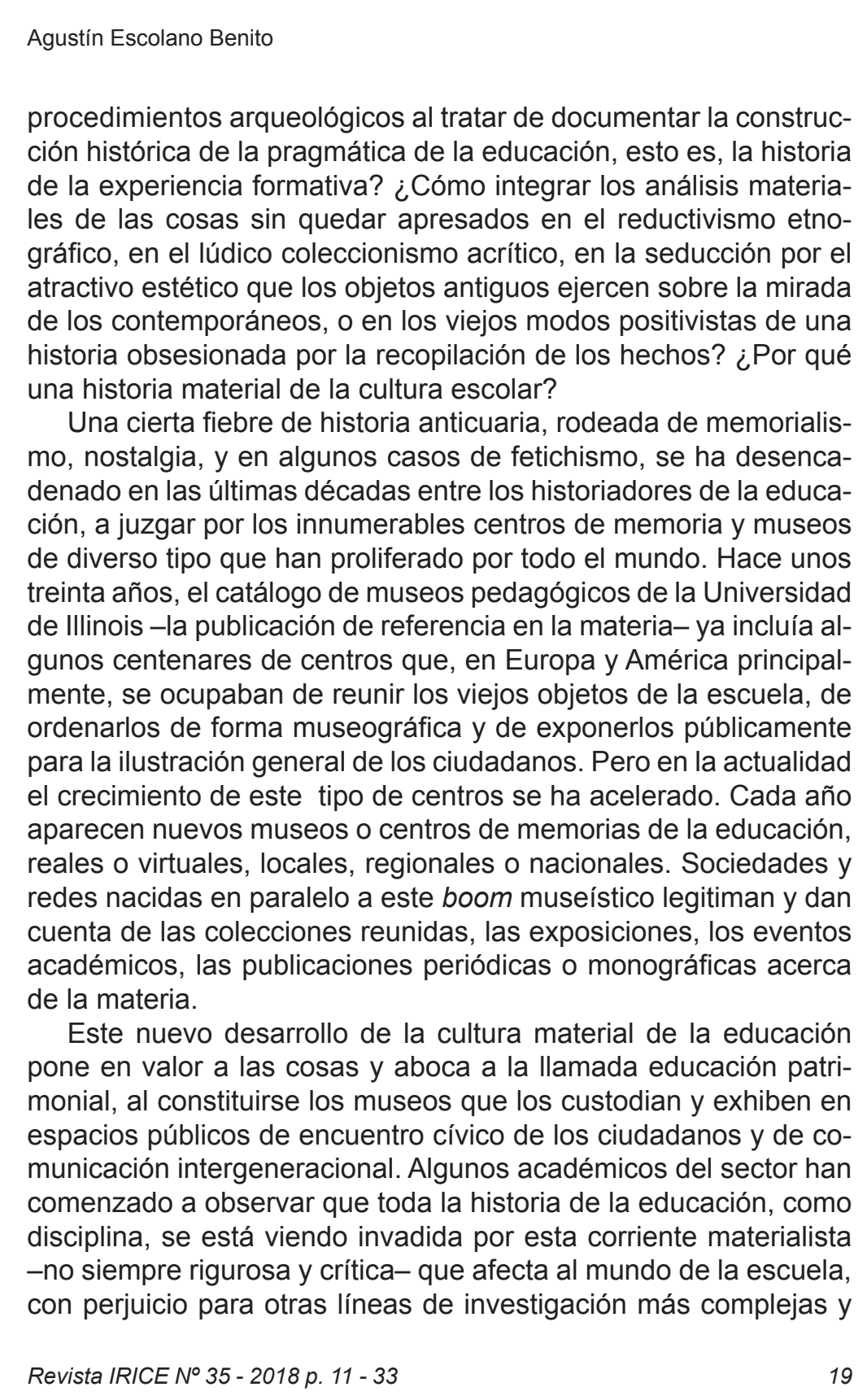


también necesarias del campo intelectual de la formación en sus proyecciones culturales y sociales. Pero esta reivindicación no puede neutralizar el legítimo interés por los objetos que están en la base de la historia de la experiencia, una historia que se plasma siempre en la cultura implícita que reside en las cosas materiales y en las representaciones. La crítica histórica ha de tratar de integrar esta nueva vía de trabajo y de acceso al conocimiento en planteamientos intelectuales más complejos, pero reconociendo al mismo tiempo el valor cultural que poseen las cosas materiales.

\section{Los objetos como sintetizadores}

En esta reconversión hacia lo empírico conviene asumir de entrada que los objetos no son meros dispositivos funcionales. La historia material se construye a partir de ellos pero va más allá de la simple operatividad y analítica de las cosas que examina. En una reciente obra, que es en realidad un narratorio biográfico de un agente de difusión y animación cultural, autor de montajes museográficos, se profundiza en la interpretación de la carga semántica adherida a los objetos a través de su diseño, de su función y de su estética, que es en verdad la primera constatación del valor que poseen ciertas cosas como fuentes sintetizadoras de una cultura. Tomaré como pretexto algunas sugerencias de este trabajo, que considero a nuestros efectos sumamente sugerentes, y con ello propondré, a modo de ensayo, alguna vía de acercamiento a las materialidades físicas que han acompañado a las experiencias vividas en los contextos reales de la escuela (Wagensberg, 2014).

Todo objeto que tiene éxito en su implantación y en la duración de su uso es una materialidad que se va cargando de cultura en el tiempo, y esta cultura suele ser la resultante de la fusión entre diversas valencias: la que afecta a su perfil (que sería a estos efectos su diseño formal); la que se asocia a su utilidad (funcionalidad que remitiría a su pragmatismo); y la que se expresa en su belleza (la dimensión estética de la cosa). Vitrubio decía algo parecido cuando evaluaba una buena fábrica o arquitectura. Esta, para ser ejemplar, debería reunir la condición de la firmitas (solidez en diseño 


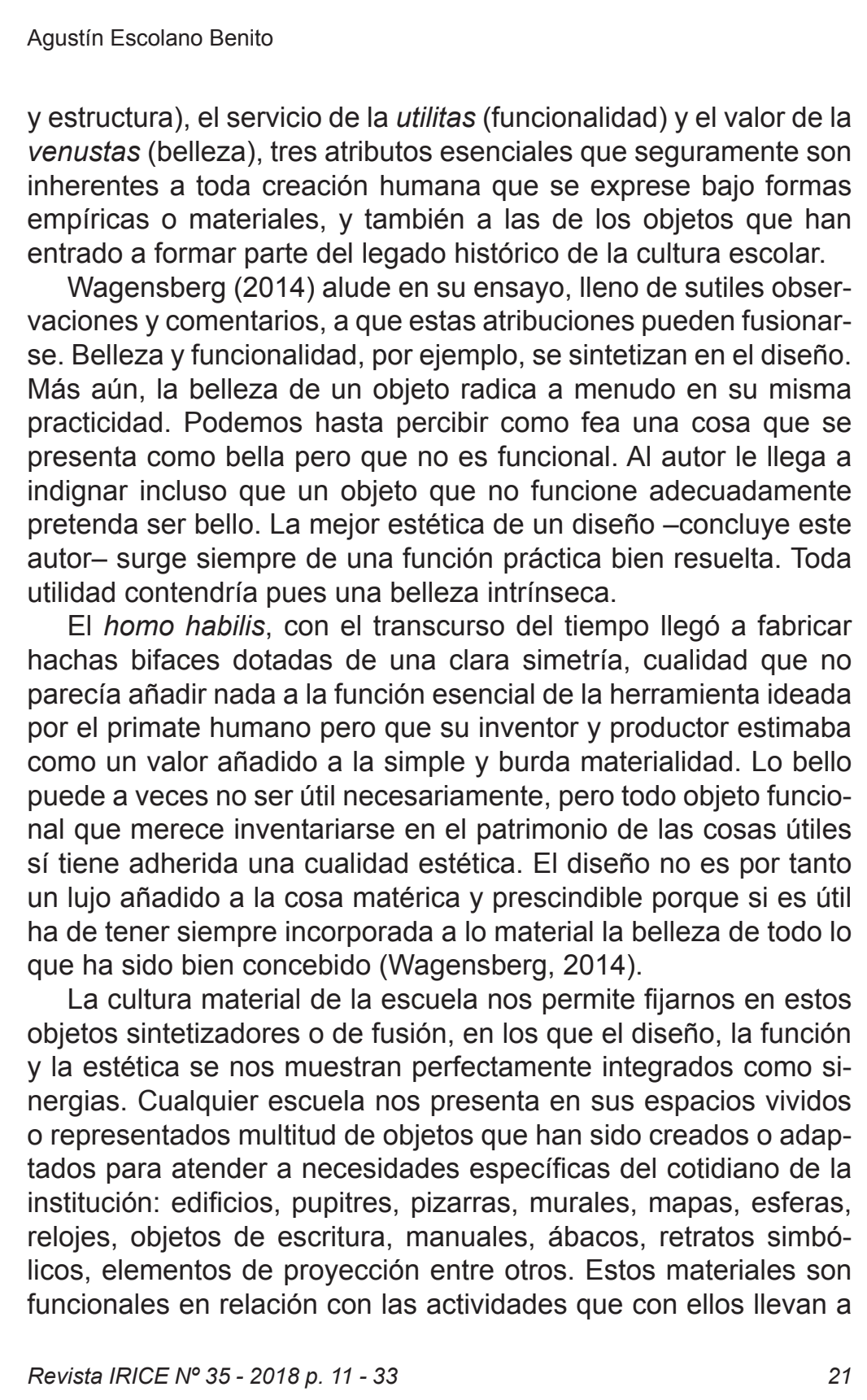


cabo alumnos y profesores, pero también están dotados de una determinada semántica y de una estética que incorporan como atributos culturales, unos inherentes a su mismo diseño original y otros incorporados en los tiempos en que han circulado. Los primeros serían los atributos propios del objeto escolar. Los otros reflejarían la historicidad adherida en las metamorfosis sufridas por las cosas materiales para adaptarse a las exigencias de cada época, o las que han derivado de las diversas apropiaciones culturales. También existen diseños formales que, aunque con estas variantes históricas, muestran un determinado formato, en cierto modo algorítmico, que se ofrece como un pattern estructurante de la cultura física de la institución educativa.

Bruno Munari, uno de los pioneros del arte proyectual, insiste en que el diseño de un objeto nace siempre de una necesidad, esto es, no es nunca una propuesta formal caprichosa. De la necesidad emerge un proyecto de concreción material y el orden lógico de su producción y modelado, basado en la experiencia y en la regla económica de lograr el mejor resultado con el menor coste y esfuerzo (Munari, 2016). Partiendo de este supuesto, un historiador de la escuela debería preguntarse, por ejemplo, por qué los pupitres modernos -nos serviremos de uno de los objetos escolares mejor definidos y con mayor grado de identidad y universalidad al tiempo- sustituyeron en el tránsito del siglo XIX al XX a los bancos corridos y a otros muebles arcaicos que se instalaron en las antiguas aulas, y que no resultaban ya funcionales en orden a cubrir las exigencias de la nueva organización colectiva, simultánea y graduada de la enseñanza.

Si observamos las dos fotografías de una clase que se muestran (la primera correspondiente a una escuela elemental valenciana de finales del siglo XIX y la segunda a un cartel de la exposición del Centro Internacional de la Cultura Escolar [CEINCE], aunque procedente del Museo Pedagógico de la Universidad de Huelva) podemos tratar de analizar los atributos que se pueden asignar a uno de los elementos materiales más característicos de la escuela: el pupitre. $Y$ tras este examen, podemos también interpretar los significados y el sentido que este común elemento adquiere en 
la cultura escolar. El cambio de diseño, de usos funcionales y de estética de este modelo respecto a otros muebles que poblaron las escuelas en el siglo XIX sugiere sin duda que en este ciclo histórico se ha operado un cambio cultural que guarda relación con los procesos de modernización de la escuela que se produjeron en la España de entresiglos XIX-XX. El cambio es aplicable asimismo a otros lugares de Europa y América.

Como puede observarse, los pupitres que se ofrecen en una y otra imagen introducen una determinada geometría en la clase compatible con una utilización máxima y óptima del espacio del habitáculo, siguiendo en esto la ley económica de todo diseño inteligente antes comentada. Esta ocupación topológica facilita la ubicación ordenada y graduada de los sujetos, y solo deja libres en horizontal los espacios por los que han de circular los profesores y monitores que guían y controlan la actividad que se desarrolla en las aulas. Nada escapa a esta planificación que no hace concesiones a la previsión de espacios libres y superfluos. Al fondo de una de estas imágenes aparece la tarima elevada, en la que puede situarse el enseñante para dirigir las operaciones de la clase y para ejercer su autoridad en la gobernanza de tiempos y movimientos de la enseñanza y el estudio, mientras los tutores se mueven por los pasillos controlando la actividad de las menores (en este caso niñas). Las paredes de los muros -todas ellas profusamente ilustradas (horror vaccui)- son soportes de láminas instructivas o de imágenes simbólicas (en un caso de carácter religioso) que decoran el espacio amueblado. Simetría, ordenación y jerarquización son los criterios dominantes en este hábitat amueblado con pupitres.

Tal ecosistema es en realidad un aula adaptada a las exigencias de la enseñanza graduada y colectiva que se imparte en su interior y responde a la necesidad de organizar de otra manera el espacio destinado a la educación de la infancia, como otros modelos aplicados en el orden doméstico que analizó Bruce L. Archer (1966). El esquema sitúa a los menores de menor a mayor edad y estatura con pupitres construidos según índices antropométricos que se acomodan a la vez a los ciclos de la graduación escolar. 
Estos muebles facilitan al tiempo la enseñanza frontal desde el punto elevado en que se sitúa el maestro y la atención individualizada que cubren los monitores de apoyo. Quien ideó este modelo de pupitre a instancias de las exigencias del sistema dio origen además a un desarrollo industrial del objeto, esto es, a su producción en serie.

Bruno Munari analizó varias exigencias específicas de un modelo proyectual que pueden ser aplicadas a este elemento esencial del amueblamiento de una escuela primaria: utilización máxima y óptima del espacio disponible (observable en la ya comentada geometría del aula); iluminación ambiental adecuada a la función de aprendizaje (la luz bilateral que llega a la superficie de los pupitres); neutralización de ruidos interiores (asegurada por el anclaje de los muebles); circulación del aire (ventilación por ventanas y pasillos interiores): materiales saludables al tacto (superficie de madera) (Munari, 2016). A estas podemos añadir otras características como la ergonomía que favorece la posición del asiento, la acomodación corporal correspondiente y la coordinación visomotora en las actividades de lectura y escritura que son las prácticas escolares más frecuentes. El modelo también responde a las exigencias de la higiene, reforzada aquí con la elevación del pupitre respecto de la superficie del aula y las condiciones ergonómicas anteriormente señaladas.

En otro orden de cosas, ambas aulas están dispuestas para favorecer un determinado tipo de sociabilidad. El modelo de pupitre bipersonal propone una interacción dual, aislando cada par de sujetos del resto del colectivo de la clase. En espacios anteriores, la relación entre los alumnos era menos definida, o si se quiere, más indeterminada. Ahora el pupitre moderno se convierte en un dispositivo de biopoder y control de los cuerpos y de una estructura colectiva del grupo que asegura el control de la población infantil sobre un pequeño territorio -el aula- en términos disciplinarios de seguridad, una versión de los mecanismos de poder y gobernanza que estudió Michel Foucault (2008), en este caso a escala de microfísica. 


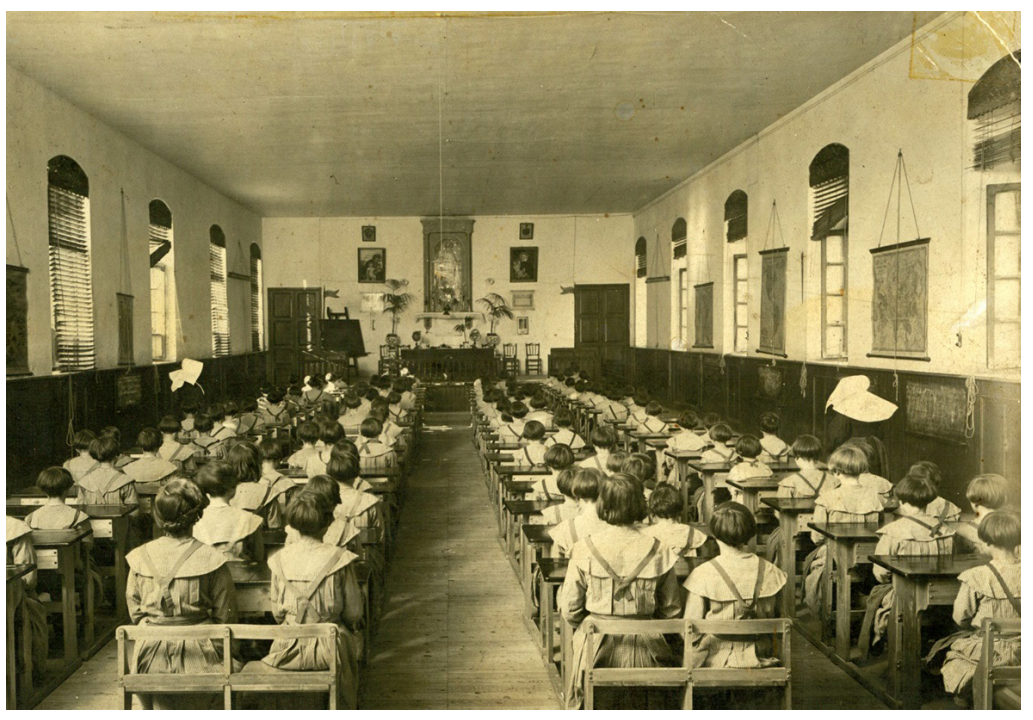

Imagen de escuela de niñas de la beneficencia valenciana, correspondiente a 1898, regentada por monjas de congregación religiosa. Cerca de un centenar de niñas, un colectivo numeroso, están rigurosamente asentadas en pupitres. El nuevo mueble, diseñado para cubrir las necesidades de la enseñanza colectiva y graduada, permite este tipo de organización del trabajo.

El pupitre, además de comportar esta inteligencia implícita en su misma materialidad y en la organización del espacio escolar, puede implementar determinados nuevos modos de sociabilidad, facilitando prácticas formales y no formales de convivencia en el contexto de una definida cultura escolar. El modelo que aquí se ofrece, en las dos representaciones, aboca a lo que el semiólogo de Bolonia, Pier Paolo Sacchetto, uno de los primeros analista del tema, denominó la "escuela inmóvil", un tipo de organización fixista que anunciaba el taylorismo y que trataba de neutralizar cualquier movimiento espontáneo de los sujetos por su riesgo de ruptura con un orden que venía prefijado por el ojo panóptico del enseñante situado en el frontal de la clase (Sacchetto, 1986). La etnohistoria podría examinar las persistencias e innovaciones en 


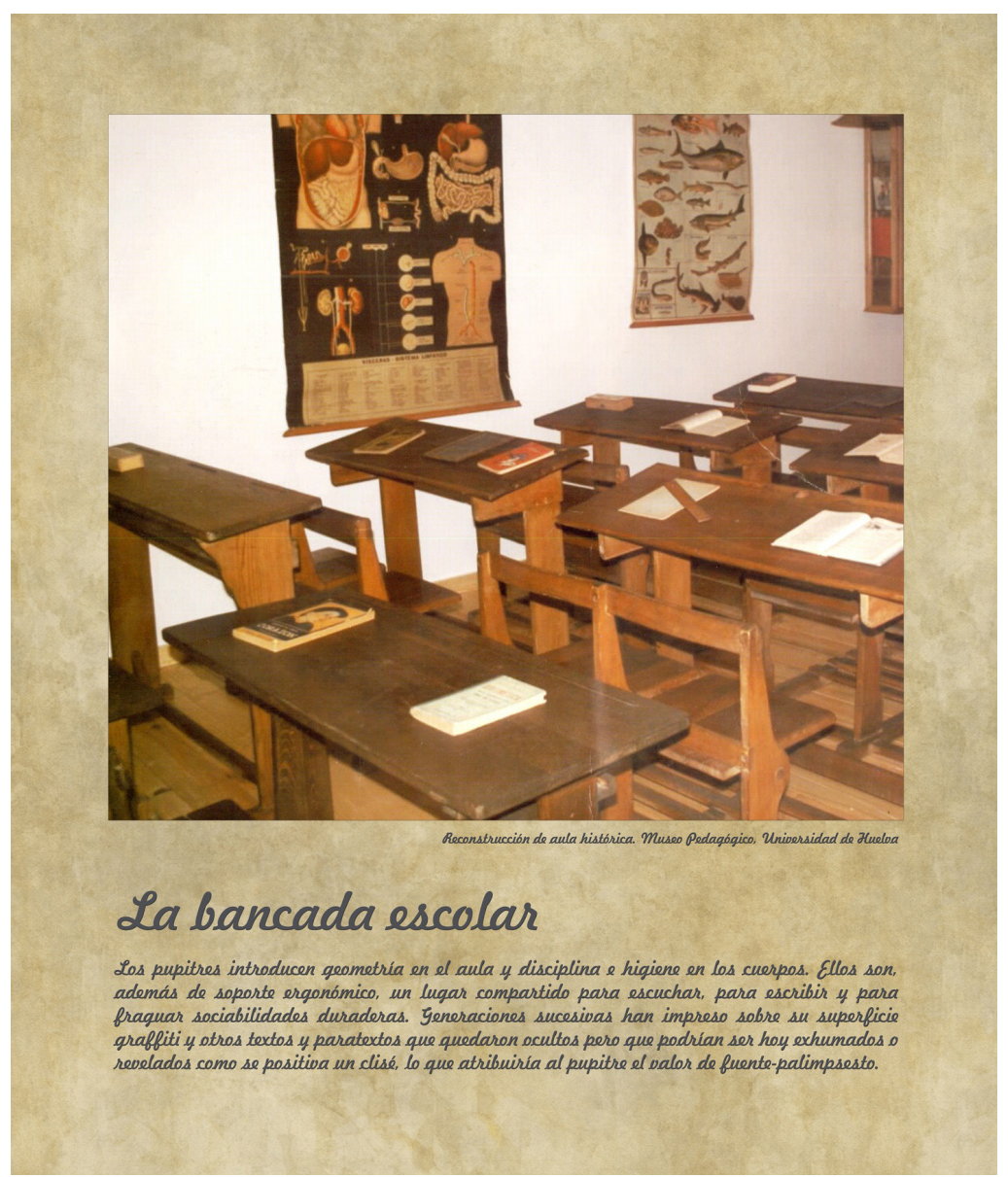

Montaje del Museo Pedagógico de la Universidad de Huelva que ejemplifica un modelo genérico de aula de comienzos del siglo XX. La bancada escolar, mostrada a sujeto vacío, responde a la misma lógica geométrica y pedagógica comentada. 
la pragmática de la escuela a partir de la observación de las tradiciones y cambios que se han ido operando en el diseño y disposición del moblaje de las aulas. El paso de estos esquemas de amueblamiento a las mesas móviles, por ejemplo, se correspondería a una nueva orientación organizativa derivada del movimiento en favor de los agrupamientos flexibles y las escuelas abiertas.

\section{Etnohistoria y pragmática de la escuela}

Los útiles que nutren las colecciones etnográficas, o sus representaciones, nos suscitan estudiar la historia de la escuela a partir de estas concreciones materiales. Los objetos, una vez sustraídos de sus ámbitos de uso y ubicados en una exposición, en un museo o incluso en un catálogo, se tornan en objetos "semióforos", esto es, se convierten en materiales que portan significados que hay que descifrar a partir de los indicios que sugieren al observador (Ginzburg, 2000). Estos significados se basan también en la historicidad añadida como plusvalía semántica a los objetos en su circulación por culturas y ciclos temporales diferentes.

A ello se ordena precisamente el conocido paradigma indiciario que el autor de El queso y los gusanos propuso como estrategia de investigación al estilo de Sherlock Holmes, un modelo heurístico que se sirve de la sospecha (la hipótesis abductiva en la lógica de Peirce) y de las huellas (las señales probatorias) para desvelar las claves subyacentes en los testimonios físicos y en los vestigios, síntomas e indicios que examina. Desde esta propuesta, los viejos objetos de la escuela, y también los nuevos, se concebirían, como hizo Pier Paolo Sacchetto (1986) en su citado estudio, como objetos-huella que cuentan cosas relevantes -no siempre bien conocidas- de nuestro común pasado formativo, y que de algún modo constituyen las fuentes documentadas con las que construir la misma historia de la escuela como institución social gobernada por prácticas empíricas en las que intervienen materialidades.

De algún modo, como advirtió Umberto Eco, el historiador de la vida material puede incluso ver en un descampado inculto algún indicio de cultura, al igual que un detective podría descubrir una huella en un campo cultivado. Estas acciones son semióticas. Y la 
historia es una práctica intelectual semiótica por excelencia, toda vez que da nombre a los restos que le sirven de fuentes y se sirve de los indicios que observa para atribuir significados a las huellas de los objetos e imágenes que encuentra. A fin de cuentas, el relato histórico es una reconstrucción de los significados de las cosas del pasado a partir de las señales que ofrecen los testimonios que nos merecen credibilidad. Sólo otorgando confianza a este discurso interpretativo trascendemos lo idiográfico y entramos a formar parte de una tradición cultural compartida (Eco, 1994).

La etnohistoria se comportaría en cierto modo como la ciencia médica que construye sus diagnósticos a partir de los síntomas clínicos observables, como el arte de la caza que se elabora a partir de olores, huellas y otras trazas o estelas que los animales dejan a su paso sobre el territorio, o como la estrategia del detective que basa su conocimiento en señales, asociaciones y conjeturas que suscitan hipótesis de relación entre ellas. Con estos mimbres, e incluso con los que derivan de las formas mudas o silenciosas y de los descubrimientos que proporciona el azar, la imaginación y la inteligencia creativa -los que Ginzburg (1994) acoge bajo el nombre de serendipity- se construye la lógica de la investigación en el paradigma indiciario. Todas estas señales e indicios, como lenguajes y sistemas de significación que son, pueden conducir finalmente a la composición de un texto, así como a introducir el trabajo científico en el campo de la semiótica de la cultura, tal como propuso Jurij Lotman (Eco, 1994).

Los objetos-huella poseen, además de estas marcas o señales, un poder narrativo, al servir de materiales en los que se apoya la construcción de relatos, y por eso justamente se transforman, diferenciada o conjuntivamente, en textos que, como escrituras creadas o dispuestas para examen, pueden ser leídos e interpretados en su forma y en los contenidos a que se asocian. Ya se sabe que fue Hayden White quien llamó la atención acerca del contenido de la forma, proposición que aludía no sólo a los modos de expresar la narratividad sino también a las transformaciones que los sujetos hacen en los textos que construyen y leen al apropiarse desde el presente de un pasado del que seguramente desearían haber 
Agustín Escolano Benito

descendido. De esta suerte, la nueva hermenéutica, de Gadamer a Ricoeur, y también de Foucault a Derrida, buscaría inscribir e interpretar los textos en contextos y en discursos, jugando con la semiología, y también con la fenomenología, el análisis de lenguaje (verbal e iconográfico), la arqueo-genealogía de las palabras y las cosas, la deconstrucción de la gramática visible y no visible en los objetos y el construccionismo intersubjetivo (White, 1992). Por esta vía justamente los objetos de la escuela se ofrecerían como fuentes primarias de conocimiento en los procesos de elucidación del sentido que subyace en la cultura de la que son portadores.

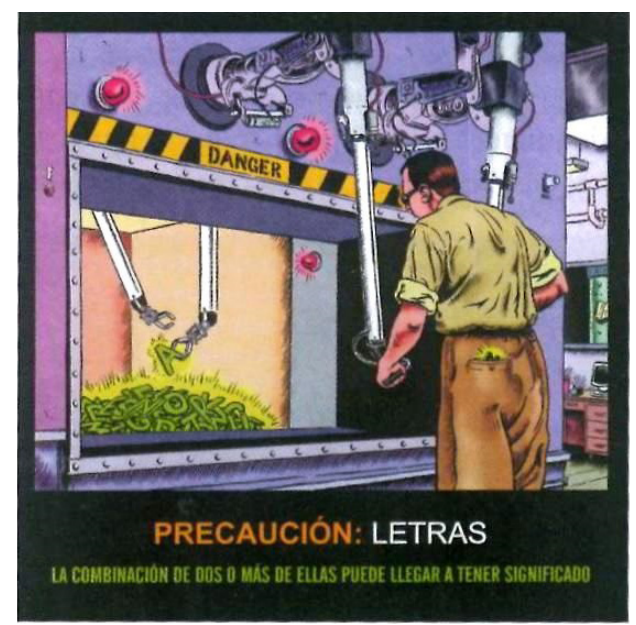

\section{JUEGOS SEMIÓTICOS CON OBJETOS E ICONOS}

El analista de los objetos del pasado puede proceder como sugiere el grafista español Miguel Brieva en la viñeta que se muestra. En el horno de la imprenta bullen las letras metálicas para componer textos. El letrero DANGER advierte al jugador que maneja las letras con garfios imantados que la asociación de unas letras con otras puede llegar a producir significados. Lo mismo puede ocurrir asociando unos materiales con otros, una relación que abocaría a la creación de un "sistema de objetos", como vio Jean Baudrillard. 
Cultura material e historia de la experiencia

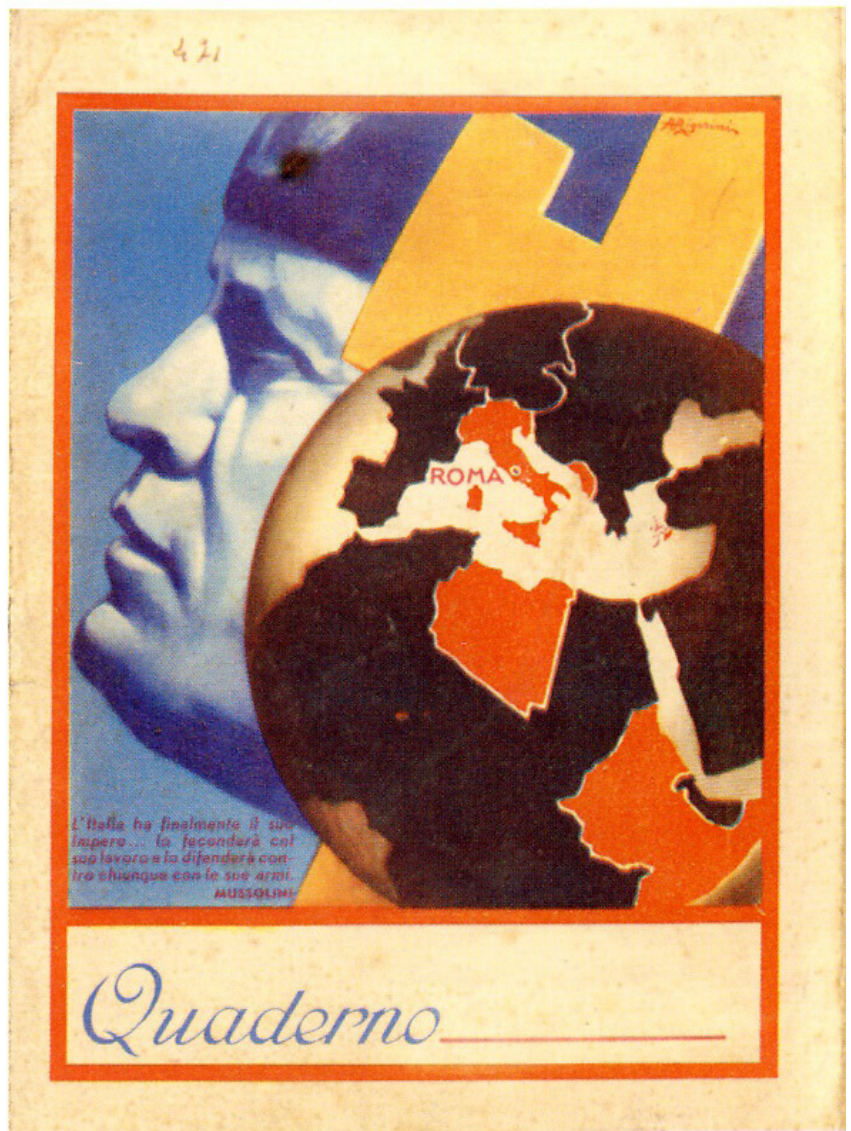

La segunda imagen procede de un cuaderno escolar italiano del período fascista. En ella el ducce Mussolini expresa, bajo el lenguaje del sueño esférico, su ambición imperialista, un leitmotiv que acompañó a la infancia escolarizada en la época del ventenio que precedió a la segunda guerra mundial. Todo un mitologema iconográfico. 
El pasado ha dejado de sí mismo en los textos y objetos imágenes comparables a las que la luz imprime sobre una placa sensible, anotaba Walter Benjamín recordando un escrito de 1930 de André Mongland, y sólo el porvenir -no su presente- poseería los "reveladores" químicamente activos para poner de manifiesto el contenido y las formas de aquellos viejos clichés. Muchos de estos testimonios encierran pues un cierto sentido que los primeros lectores no podrían descifrar plenamente, responsabilidad que quedaría adscrita a los herederos del legado, o sea, a los historiadores (Benjamín, 2005). Ello nos invita ahora a desvelar la caja negra de los bienes que hemos recibido como patrimonio y nos previene a que tal vez nuestro tiempo tampoco esté en condiciones de percibir los rasgos y las consecuencias culturales del giro tecnológico que está generando una nueva revolución en los modos de producción y en los objetos e iconos de que se sirve la nueva cultura de la escuela. Esto es obvio, aunque tampoco hoy sería acertado sostener que el desvelamiento de los códigos que están implícitos en las huellas del pasado pueda ser tan objetivo como el que se derivaría de un revelado mecánico de los clisés conservados que hemos recibido. No hay que olvidar que, como ha puesto de relieve la teoría de la recepción, tales lecturas y apropiaciones están sujetas también a procesos de subjetivación y adaptación, siempre determinados por la perspectiva hermenéutica pluritópica de la diversidad, la que aplican los sujetos y los grupos que leen e interpretan los restos arqueológicos de la escuela tradicional y los lenguajes que acompañan a sus fuentes materiales.

El descifrado pues de las señales que nos envían los objetos-fuente del pasado es una operación sujeta en todo caso al consenso o a la percepción de la diferencia que deriva del juego de la intersubjetividad de las miradas e interpretaciones. Su lenguaje es exponente, afirma Diana Gonçalves Vidal, releyendo a Michel de Certeau, de una mezcla semántica entre el intento de recomponer sus usos y significados originarios y todas las interpretaciones posibles que derivan de otros registros y otras atribuciones (Gonçalves Vidal, 1999). No hay que olvidar que, como advirtió Junichiro Tanizaki en su sugerente ensayo Elogio de la sombra, "la forma de 

definitiva un capítulo -importante sin duda- de la historia de la experiencia humana, una nueva gnosis que afecta a la construcción de la subjetividad y de la civilización, y por tanto, a la antropología y a la historia misma en su conjunto.

\section{Referencias}

Archer, B. L. (1966). Systematic method for designers. London: Council for Industrial Designers.

Benjamin, W. (2005). Libro de los pasajes. Madrid: Akal.

Burke, P (2001). Visto y no visto. El uso de la imagen como documento histórico. Barcelona: Crítica.

Cohn, B. S. (1962/2001). Un antropólogo entre historiadores. Desacatos, $\mathrm{s} / \mathrm{n}, 23-35$.

Eco, U. (1994). Prólogo. En J. Lozano, El discurso histórico (s/p). Madrid: Alianza Editorial.

Eco, U. (2000). Los límites de la interpretación. Barcelona: Lumen.

Escolano, A. (2007). La cultura material de la escuela. Berlanga de Duero: CEINCE.

Escolano, A. (2017). La cultura empírica della scuola. Esperienza, memoria, archeologia, Ferrara: Volta la Carta.

Febvre, L. (1953). Combates por la historia. Esplugas de Lobregat: Ariel.

Foucault, M. (1968). Las palabras y las cosas. México: Siglo XXI.

Foucault, M. (2008). Seguridad, territorio, población. Madrid: Akal.

Ginzburg, C. (1994). Mitos, emblemas, indicios. Morfología e historia, Barcelona: Gedisa.

Ginzburg, C. (2000). Ojazos de madera. Nueve reflexiones sobre la distancia. Barcelona: Península.

Gonçalves Vidal, D. (1999). A memória e a sombra. Belo Horizonte: Autentica.

Munari, B. (2016). ¿Cómo nacen los objetos? Barcelona: Gustavo Gili.

Sacchetto, P. P. (1986). El objeto informador. Los objetos de la escuela: entre la comunicación y el aprendizaje. Barcelona: Gedisa.

Sennett, R. (2006). El artesano. Barcelona: Anagrama.

Tanizaki, J. (2003). El elogio de la sombra. Madrid: Ediciones Siruela.

Wagensberg, J. (2014). Algunos años después. Barcelona: Ara Llibres.

White, H. (1992). El contenido de la forma. Narrativa, discurso y representación histórica. Barcelona: Paidós. 